INTERNATIONAL DESIGN CONFERENCE - DESIGN 2018

https://doi.org/10.21278/idc.2018.0187

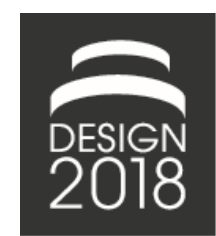

\title{
PUTTING THEORY TO PRACTICE: REFLECTIONS ON THE INTEGRATION OF PRODUCT DESIGN ASPECTS IN AAL PROJECTS
}

\author{
S. Dittenberger
}

\begin{abstract}
This paper discusses the question of the awareness and representation of product design aspects in the user-centred design's ISO process model applied in research projects in the realm of the Active and Assisted Living (AAL) Programme. Experience has shown that product design aspects are to date not as well integrated and applied in projects' everyday working practice as the realms usability engineering, user experience design and user interface design already are. This paper proposes refinements for the applied process as a basis for further elaborations.
\end{abstract}

Keywords: design process, engineering design, human centered design, user centered design, project management

\section{Introduction}

This paper discusses an observation gathered during the work on research projects in the realm of the Active and Assisted Living (AAL) Programme concerning the representation and integration of product design aspects and parameters in the project development process. The AAL programme funds research projects to foster "the emergence of innovative ICT-based products, services and systems for ageing well at home, in the community, and at work (AAL Europe, 2018)" with the goal to increase the quality of life of older adults. Projects in this realm are committed to a user-centred design process to guarantee a high level of user involvement during the technology development process. Partners from industry, research and user organisations collaborate in the realisation of funded projects in this programme. Therefore, also a combination of different disciplines, like technical engineering, system architecture, user research and design work together on the success of these projects.

Normally each of these disciplines applies their own project development process methodology in their work. When people of different fields of expertise work together on a research project like this, the selection and definition of an overall process methodology is essential to reach the defined project goals. The ISO 9241-210:2010 standard (International Organization for Standardization, 2017) is used most often in AAL projects as a process management and requirements engineering tool for the creation of computer-based interactive products and systems.

Since the focus of the challenge-led calls of the AAL programme has evolved over the years from research on computer-based interactive systems to market-oriented ICT-products, the observation was made that hardware design aspects are to date not as well integrated and applied in projects' everyday working practice as the realms usability engineering, user experience design and user interface design already are. Meeting the users' requirements for utility, safety and comfort is the primary objective for products developed in this research realm. Prototypes of the developed technology are evaluated with people of the target group with reference to their acceptance, usability and whether the 
psychological aspects for the use of the product, like motivation, well-being, self-efficacy (Kothgassner et al., 2012), are well addressed and implemented. Concerning the overall response to the products' visual form, the AttrakDiff questionnaire (Hassenzahl, 2005) is used most often to collect information about the subjective perception and usability of the developed ICT-based product. The questionnaire measures pragmatic, like effectiveness and efficiency, as well as hedonic, like fun and identification, product qualities. But apart from meeting users' requirements for utility, safety and comfort, the perceived decorative, emotional and symbolic attributes of a product are equally important for a products' success. This observation led to the question which kind of refinements the applied user-centred design's ISO process concerning the representation of the involved product design aspects would need to increase the awareness of the whole project development team and harmonize through this the daily project work. In pursuit of this aim and in order to learn from the experience of others, process structures applied in the context of user-centred and human-centred design are examined.

\section{User-centred design}

The synonymous usage of the terms user-centred and human-centred design marked the beginning of the search for refinements by looking at definitions and procedures in order to identify possible differences. As a multi-disciplinary team working together on the development of an ICT-product, it is essential not only to offer a clear and structured overview of the project's development process, but also to have a shared understanding of relevant terms and definitions.

In the realm of AAL projects the user-centred design process is widely accepted and applied. The ISO 9241-210:2010 standard (Figure 1), Ergonomics of the human-system interaction -- Part 210: Humancentred design for interactive systems, is most frequently used within the user-centred design process to guarantee a high level of user involvement during the technology's development.

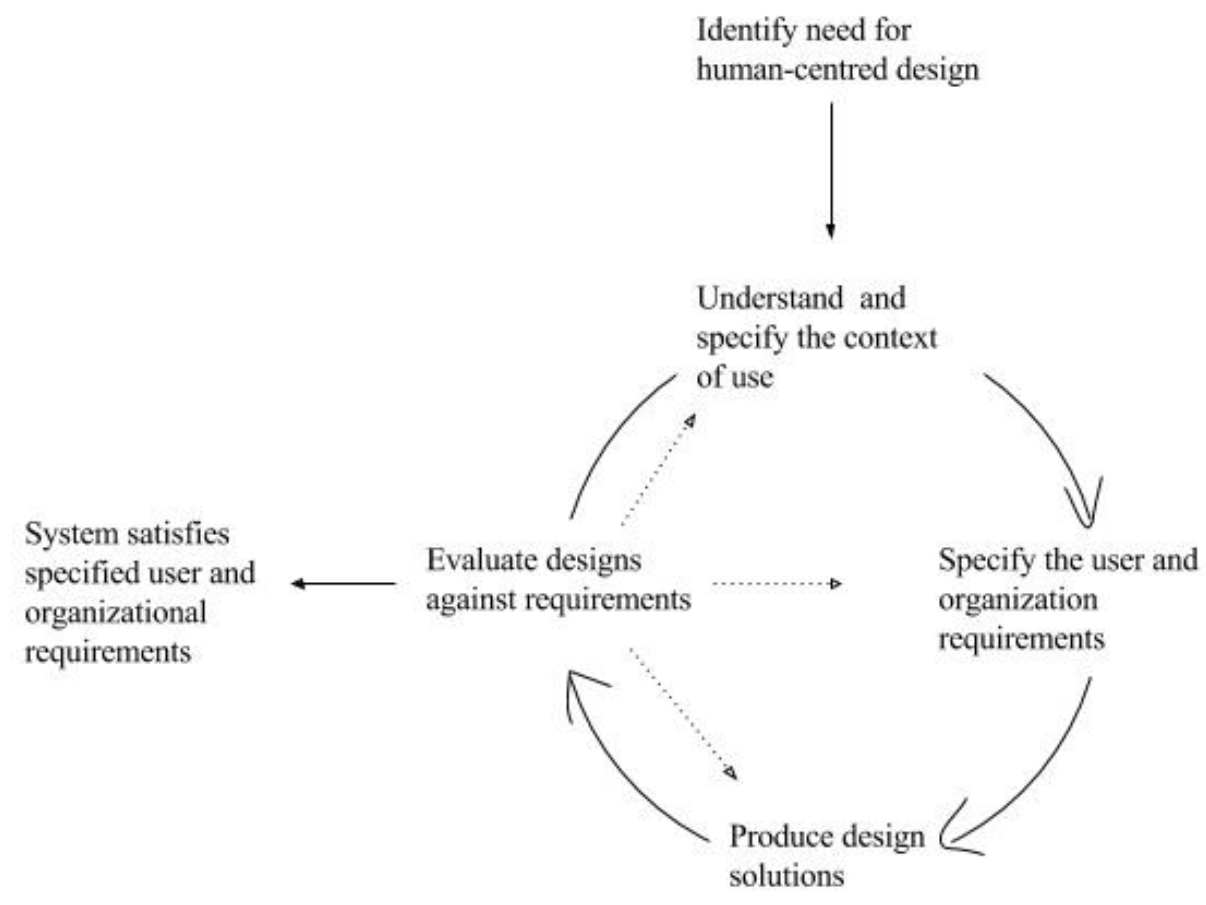

Figure 1. User-centred design process methodology - ISO 9241-210:2010 Standard (own representation based on International Organization for Standardization, 2017)

The use of international standards is important since they "provide requirements, specifications, guidelines, or characteristics that can be used consistently to ensure that materials, products, processes and services are fit for their purpose (International Organization for Standardization, 2017)". The 
international standard 9241-210:2010 provides requirements and recommendations for human-centred design principles and activities throughout the life cycle of computer-based interactive systems. It is intended to be used by those managing design processes, and is concerned with ways in which both hardware and software components of interactive systems can enhance human-system interaction.

Starting after the identification of the need for the application of a human-centred design process for the development of a product, the iterative process is characterised by four phases. Phase 1 is intended to understand and specify the context of use of the project. Technical as well as user requirements are collected in this phase. In phase 2 the collected technical and user requirements get listed and personas, uses-cases as well as scenarios are developed. During phase 3 design concepts and prototypes are created in order to evaluate them in phase 4 against the collected requirements of phase 2 . In an iterative manner, the phases get repeated till the evaluation results show the desired overall outcome of the project. The search for refinements of the applied user-centred design's ISO process originally started with phase 3 'produce design solutions' and phase 4 'evaluate designs against requirements' about product design parameters concerning form, material and colour but got soon enlarged to all phases of the process.

\section{Human-centred design}

The discussions of the past about the subject-object relationship resulted in the definition of various design paradigms. Research areas and disciplines which focused on the creation of machines like ergonomics, informatics, and artificial intelligence were followed by the fields of human factors, usability, user-centred design, inclusivity, interaction design, empathic design, design for product experience, design for customer experience, design for emotion, emotionally durable design, sensory branding, neuro-branding and service design. These research fields share the motivation to understand what people perceive and experience during a product interaction process and what kind of meaning they attribute to products they surround themselves with.

Today, following Joseph Giacomin's (2014) statement, we have entered the design paradigm of humancentred design. In order to structure the growing complexity of design tasks today and with the focus on the examination of subject-object relationships, and relationships which are enabled through the use of products, Giacomin proposes a human-centred design pyramid as a human-centred design process methodology.

The basis of the pyramid addresses the human factors of perception, cognition, emotion and ergonomics of a human-product relationship. This is followed in the upper stages of the pyramid by more complex, interactive and sociological considerations of levels of meaning. Represented by the hierarchical composition of the pyramid from the questions who, what, when, how to why, Giacomin sees the human-centred designer as an actor who focuses foremost on the translation of human requirements to a product and not on the personal creative expression of the designer. Like the evolving definitions of the areas of the subject-object relationship, the techniques and methods of research in these areas also changed. The author points out that for each level of the pyramid different research methods could be applied, varying in the lower levels from the collection of socio-demographic to anthropometric data, and in the upper levels from ethnographic to empirical research methods.

\section{User-centred vs human-centred design}

There seems to be a general agreement that international standards like the ISO 9241-210:2010 supports effectively the gathering of user and organization requirements and with this the whole process methodology for a technology development project. But the use of standards like this also engenders critical remarks. Heimgärtner (2014) criticizes human-centred design's ISO for being too rigid to adapt to local cultural contexts. Realpe-Muñoz et al. (2016) offer criticism for the lack of adequately addressing user security and privacy. Thomas et al. (2017) add critique to human-centred design's ISO standard concerning the inclusion of the aspects of sustainable interaction design, animal-computerinteraction, and object oriented ontology.

Apart from the discussion about the content of the ISO process, also the varying use of terminology appears confusing. By looking at the graph of the ISO process model where the terms human-centred design and user is applied, at the wording of the ISO text where they use the term human-centred design, 
and at the term end-user in AAL call texts, the need to address a clarification of the terminology seems adequate.

Due to the usually pre-defined technological challenges of projects applying the ISO standard, critique arises concerning the resulting limitations of the degree of freedom of human-centred research approaches. In the paper Human-Centered vs. User-Centered Approaches to Information System Design Susan Gasson (2003) explains her view on the difference between user-centred and human-centred design projects. For her, the difference originates in the manner how technology is developed and concludes that the user-centred approach aims at working on pre-defined technology-centred problems and the human-centred approach is concerned with research on how humans can be supported in their everyday lives through the use of technology.

Joseph Giacomin (2014) states that human-centred design is not focused only on research whether products are understood by their intended users but also what kind of meaning they entail for them. Furthermore, the difference between human-centred design and industrial design lies for Giacomin in the fact that human-centred design focuses on the questions, life contexts and activities of the persons of the target group and not on the personal creative expression of the designer or material and technology-centred approaches. For him, human-centred design generates products, systems and services which are physically, cognitively, emotionally and intuitively understandable.

With reference to the search for refinements for the applied user-centred design's ISO process, Giacomin offers an inspiring approach. The AAL programme funds the development of ICT-based solutions in response to individual and societal challenges. The actual project work starts with a pre-defined technological challenge. As a refinement, and in order to identify individual and societal challenges, the inclusion of Giacomin's process with the focus on life contexts and activities of humans could be considered as a preparation of the phase 'identify need for human-centred design' of the applied usercentred design's ISO process.

\section{Co-design and co-creation}

Steen (2011) summarizes six overall approaches which are currently used by researchers and practitioners in human-centred design projects: participatory design, ethnography, the lead user approach, contextual design, co-design, and empathic design. Sanders and Stappers (2008) describe the shift from a product-related handling of a design task to a human-centred and product-meaning one as an evolution from a user-centred to a co-designing approach. They point out that " the best known proponents of co-design originate from business or marketing and not from design practice $(2008, \mathrm{p} .8)$ ". Prahalad and Ramaswamy (2004) discuss the co-creation process of value creation with customers, Tseng and Piller (2003) address the co-creation process of value between companies and customers, von Hippel (2005) points to the importance of the involvement of lead users in co-creative processes and Seybold (2006) includes the creative lead customers in her work.

Sanders and Stappers (2008) argue that design cannot longer be thought of in terms of product categories but in terms of designing for people's purposes. They name as traditional design disciplines visual communication design, interior space design, product design, information design, architecture and planning and see the emerging design practices in the disciplines design for experience, design for emotion, design for interacting, design for sustainability, design for serving and design for transforming. In their view product designers won't be obsolete in future and point out that their special skills will become even more important in these new emerging design practices. In the publication Convivial Toolbox: Generative Research for the Front End of Design Elizabeth Sanders and Pieter Stappers (2012) proclaim that the design development process has severely changed over the last ten years and that design today deals not exclusively with the designer's individual creativity any longer but with the fulfilment of wishes and needs of the people we design for.

This shift in mind-set has led from a traditional user-centred design process, where the user is a passive object of study, the researcher offers input on theories as well as results of user studies and the designer receives all this input to develop an overall concept and design for the project at hand, to a co-design process, where the end-user of a product is a part of the development team due to his role of being an expert of his or her experience (Figure 2). 


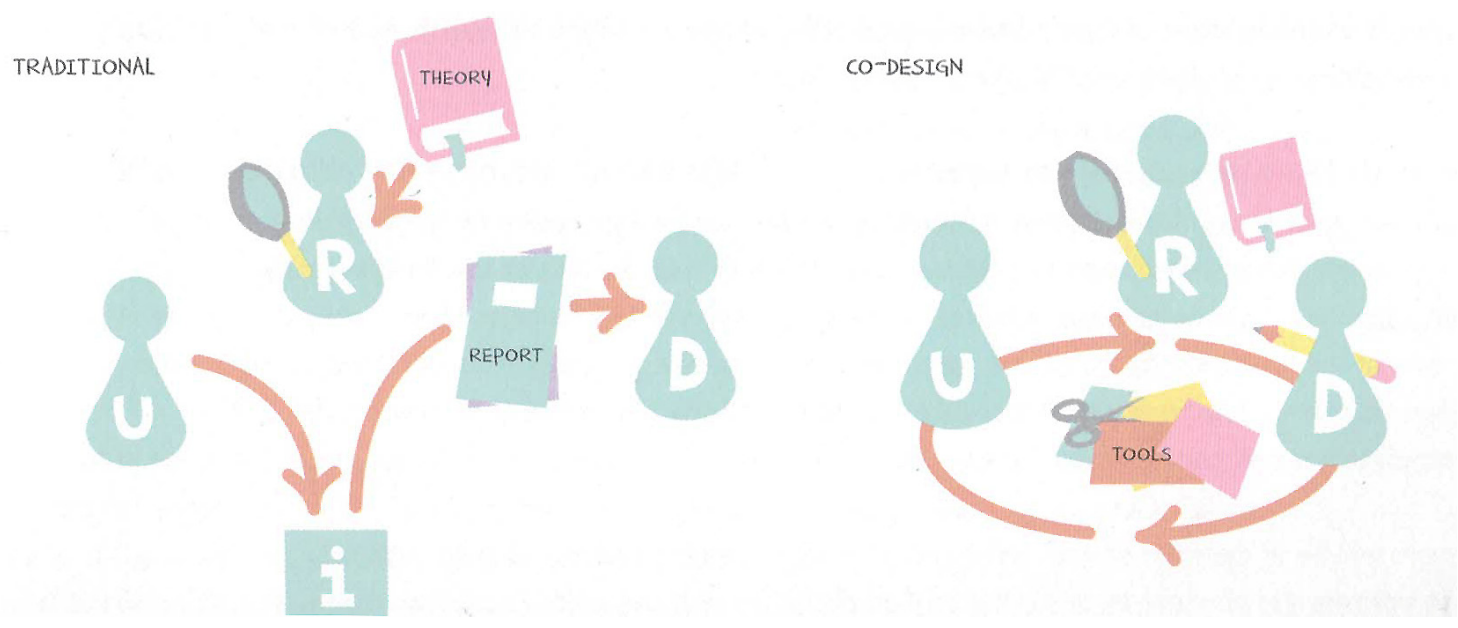

Figure 2. Co-design process (Sanders and Stappers, 2012)

By means of building an overall design process methodology the term co-creation is used to include monetary values, use/experience values and societal values in the process methodology. Sanders and Stappers (2012) describe the design development process of a co-creation project with six steps. The first step builds the pre-design phase. In this step research is conducted and problems concerning the tasks get defined. Step two, discovery, research findings should build the basis for the creation of design concepts. In step three, design, these developed concepts should progress, get explored and prototyped. The output of this phase builds the selection of a final design solution. During step four, making, the selected design solution gets optimized for manufacturing and the production process. Marketing is the fifth step and deals with the product's roll-out, distribution and sales aspects. Finally step six, after sales, represents the phase where the product's use and service experience happens. In their view co-creation can take place at any point of this design development process (Figure 3).

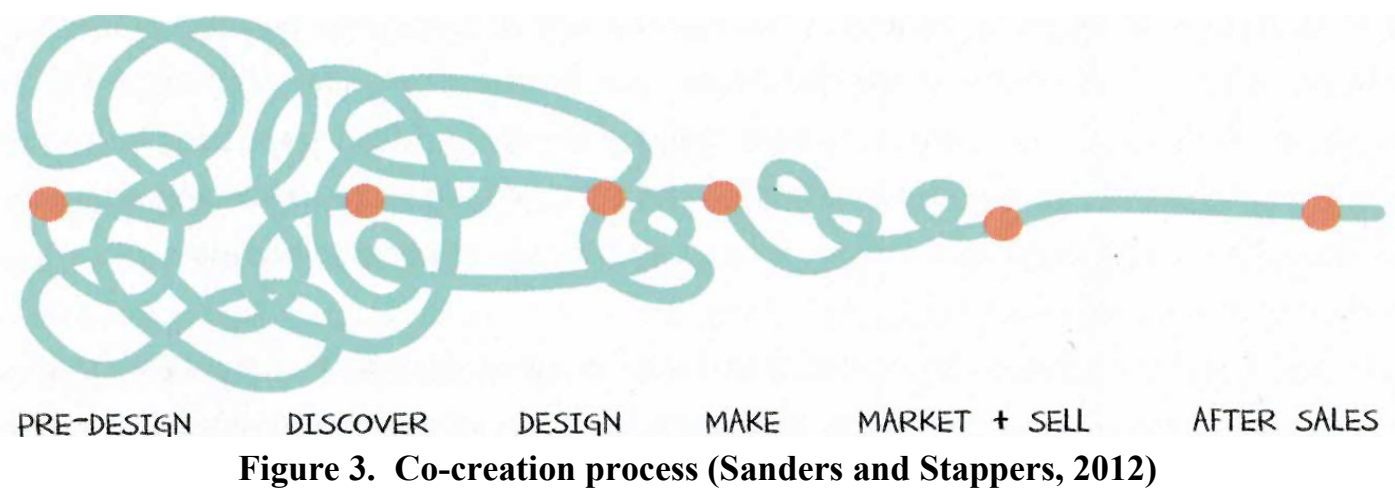

\section{Design thinking}

Today, the involvement of humans in the design process is often put on a level with design thinking projects. The term design thinking was coined by the design and innovation firm IDEO and their process methodology is now widely discussed as well as practiced in human-centred design projects. In the publication The Field Guide to Human-Centered Design it is stated that "[h]uman-centered design offers problem solvers of any stripe a chance to design with communities, to deeply understand the people they're looking to serve, to dream up scores of ideas, and to create innovative new solutions rooted in people's actual needs (IDEO.org, 2015)".

Brown (2009) describes the three spaces of innovation of design thinking projects with: inspiration, ideation and implementation. Plattner et al. (2009) divide the design thinking process in the steps: understand, observe, define point of view, ideate and test. And according to the publication Design Thinking for Educators a design thinking project (Figure 4) is divided in the steps: discovery, 
interpretation, ideation, experimentation, and evolution (Design Thinking for Educators, 2012). The phase 'discovery' includes the steps understand the challenge, prepare research, and gather information. The next phase 'interpretation' is divided in the steps tell stories, search for meaning and frame opportunities. Ideation, the third phase, includes the steps generate ideas and refine ideas. In the phase 'experimentation' the steps make prototypes and get feedback are included. Finally the phase 'evolution' entails the steps track learnings and move forward. The involvement of humans in each of these process steps builds the foundation for any design activity therein.

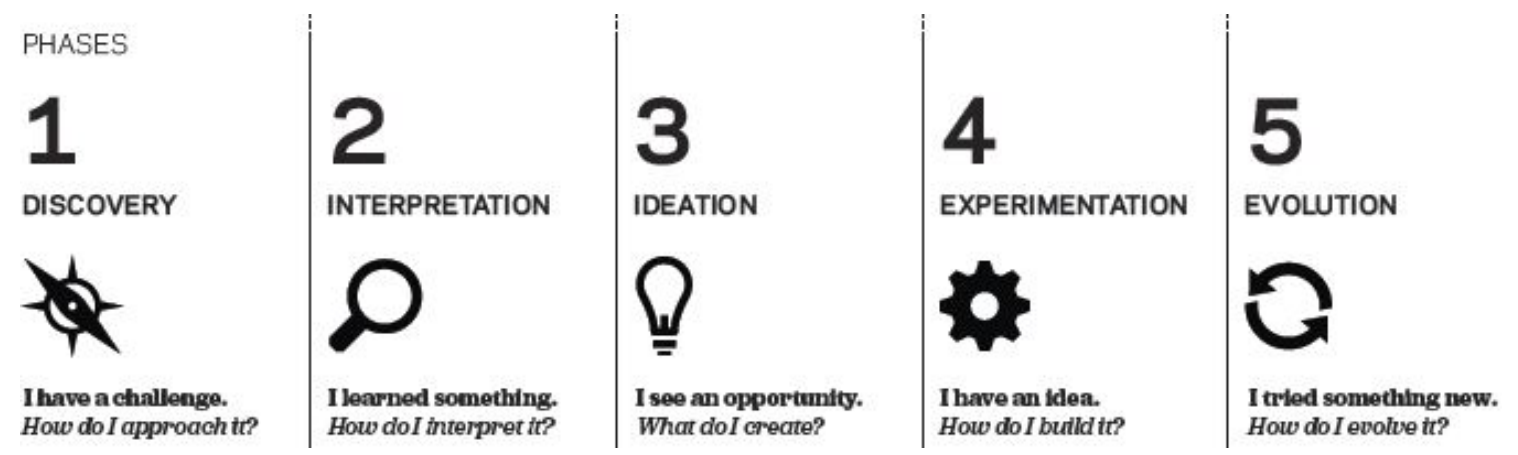

Figure 4. Design thinking process (Design Thinking for Educators, 2012)

\section{Product design}

The importance to address the human aspect of design in a product development process is nowadays widely recognized and gets slightly different applied in various disciplines. The deeper a discipline got engaged into the research on the subject-object relationship, the more research areas emerged. As a consequence, varying approaches and methods were created from each of the disciplines, like industrial design (Milton and Rodgers, 2013), usability engineering (Richter and Flückiger, 2013), user-centred design (Cockton et al., 2016), user experience design (Diefenbach and Hassenzahl, 2017), inclusive design (Eikhaug, 2012), and design for emotion (van Gorp and Adams, 2012), referring to the question what human-centred design is and how best to involve humans in the design process.

The steady technological advancements, and the fact that almost every product today is to some degree intelligent, emphasize the precondition that a set of multiple disciplines are needed for the creation of technology and design. Gerhard Heufler (2016) from the field of industrial design proclaims that, in future, design needs to intensify the cooperation with experts from different professional disciplines to be able to face the increasing complexity of the design challenges ahead. He sees a necessity for the application of new methods of cooperation across disciplines to give rise to new innovative product solutions. Ken Friedman supports this arguments and points to the blurred "boundaries between artifact, structure, and process; increasingly large-scale social, economic, and industrial frames; an increasingly complex environment of needs, requirements, and constraints; information content that often exceeds the value of physical substance (ibid., 2016)". Today's fast technological development leads to the fact that our product world and even our environment get smarter every day. From a human-centred point of view, this technological evolution offers many benefits for users but bears also a wide range of possible obstacles.

From a traditional design engineering perspective, Vladimir Hubka pioneered the development of a systematic design process in engineering practice and was one of the initiators of the development of a comprehensive design science. Hubka and Eder (1996) created a map of design science and divided it in the categories design process information, theory of engineering design systems, theory of technical systems and information about existing objects. The map indicates that they addressed the human aspect of design in terms of the collection of information about physical and mental human activities and the inclusion of theories on human behaviour in design engineering. Eder (2008) offers an overview of the evolvement of Hubka's work concerning the aspects of differentiating designing in engineering, transformation systems, information, and object information as well as a design science hierarchy.

Gerhard Heufler presents a description of a design engineering process in his publication Design Basics: From Ideas to Products (2004) divided in 4 main phases (Figure 5). Phase 1 of the process, researching 
and analysing, aims to identify the problem of the design task at the beginning of the project. Afterwards research on the identified task is conducted. The collected data get sorted and analysed afterwards. In this phase, the observation of the products' target group is also included but in this publication not further explained in terms of adequate user research methods. The output of this phase is a design briefing covering the aspects of proposed usage, target group and market, as well as technical, economic and ecological requirements. A time schedule with intended milestones gets also defined.

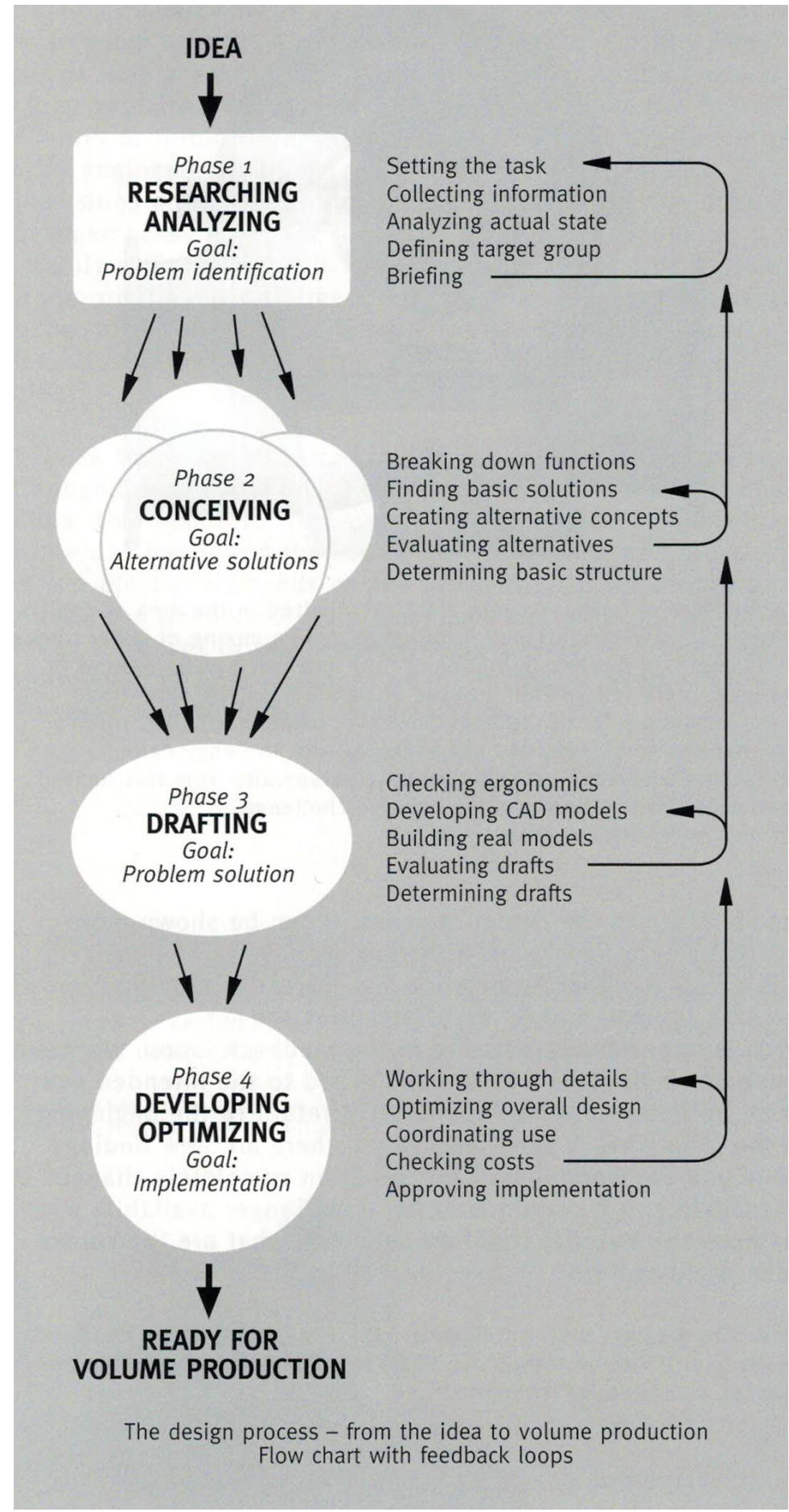

Figure 5. Heufler's industrial design process (2004) 
In phase 2, conceiving, a reference product with all additional elements gets analysed in detail. A list of all required functions is created and supplemented by a collection of overall needs concerning the product. Based on this knowledge, design concepts and alternative proposals for design solutions are developed with the help of design sketches, paper models, mock-ups, scale models and ergonomic models.

Phase 3, drafting, represents the core of the design process and entails the goal to find a solution to the defined design task. The developed design proposals of the previous phase 2 are evaluated and discussed against the collection of data from phase 1. Approaches get merged and revised to create a new design solution. This is accompanied by the production of additional product design sketches, mock-ups, 3D models, 1:1 scale models which show the intended functions and ergonomic conditions.

The final phase 4 of the process, developing and optimizing, aims at implementing the product with respect to optimization for construction and production as well as material properties. Prototypes are built and tested. The output of this phase is a working production sample which describes the start of the serial production. This process methodology is drafted not exclusively as a linear process but entails various possibilities for process iterations.

With regards to the involvement of people of the target group in the industrial design process, Heufler's publication originating from the year 2004 shows admittedly references to the conduction of user observations but offers no further explanations on how to execute them. It could be concluded that at this time, the ultimate goal was to design and produce products for humans but this task was conducted only with passive user involvement. In the fifth extended and revised edition of this book, originating from the year 2016, the author comments that the exclusive product-related handling of a design task is not adequate any longer and points to vital human-centred as well as product-meaning oriented questions which also have to be addressed in a product design development process (Heufler, 2016).

\section{Discussion}

The discussed literature inspired various ideas for refinements of the representation of product design aspects in the user-centred design's ISO process model applied for practical project work. Figure 6 displays the suggested refinements in form of colour gradations to the main colour for each project phase. As discussed under point 4, user-centred vs human-centred design, the synonymous application of the two terms bears the potential for confusion and a clarification seems indeed appropriate due to the human-centred focus of AAL projects.

We learned that the process structures of user-centred design's ISO process, co-design and co-creation, design thinking and product design share the starting point of the existence of a project idea or predefined technological challenge. Giacomin's approach to start a human-centred design project by focusing on life contexts and activities of persons inspired a reflexion of its application in the pre-project phase 'identify need for human-centred design' of the ISO process for the actual creation of project ideas. Additionally, the dealing with the roots of co-design and co-creation inspired to think about the aspect of the creation of value in this pre-project phase. As before, the output of this pre-phase would be the definition of a project idea or a pre-defined technological challenge and would constitute the change of terminology from human-centred to user-centred design.

The collection of ecological aspects of the design task, which was identified in the process structure of product design, is envisaged to refine the phase 'understand and specify the context of use'. The topic of sustainable product development should be self-evident by now but has not been adequately presented in the ISO process model. For the collection of user requirements, the methods from social science are planned to be enlarged about methods from the field of design research. The mixed-methods approach should guarantee right from the beginning of a project, not only to collect user needs and wishes but also to collect reference data concerning product design parameters for form, material and colour choice.

The next phase of the user-centred design's ISO process, 'specify the user and organization requirements', gets refined by a detailed analysis of reference products. Surely, the work on each AAL project includes an analysis of reference products to the own project idea. But with this addition we plan 
to analyse the competing products under the aspects of hardware, interface and interaction design parameters.

Crilly et al. (2004) present a literature review of the cognitive consumer response to visual product form. They state that a consumer judges a product based on the information received by the user's senses. As a result of their comparative literature review they were able to identify three categories for the description of the cognitive response to product appearance. As first category they mention the aesthetic impression in terms of the perception of attractiveness of a product. Second, they name the semantic interpretation meaning the perceived function of a product and third, the symbolic association which is defined by the message a product tells about the owner. These categories have been added to the refinement our process under the categories practical, aesthetic and symbolic product functions (Table 1).

Table 1. Practical, aesthetic and symbolic product functions

\begin{tabular}{|l|l|l|l|}
\hline & Practical Function & Aesthetic Function & Symbolic Function \\
\hline Form & handling, ergonomics & $\begin{array}{l}\text { shape, geometry, } \\
\text { material, surface, } \\
\text { colour, smell, taste, } \\
\text { sound, touch }\end{array}$ & self-representation \\
\hline Interface & $\begin{array}{l}\text { comprehensible, } \\
\text { understandable }\end{array}$ & $\begin{array}{l}\text { graphic, layout, font, } \\
\text { colour }\end{array}$ & self-expressive \\
\hline Interaction & efficient, effective & intuitive, effortless & fun, excitement \\
\hline
\end{tabular}

The output of this process phase is defined by listed requirements for the technical, ecologic, economic and user project aspects. A design briefing, including objectives for practical, aesthetic and symbolic functions of the product, is added. In order to visualize the defined requirements for the project team members, personas, use cases, scenarios and storyboards get created.

The process phase 'produce design solutions' contains the creation of design concepts based on the results of the previous process phases. The conduction of co-design workshops with people of the target group are usually an integral part of the working practice in AAL projects, but are now visibly presented in the refined process model. But nevertheless, the attitude of co-design to integrate the future users of a product as part of the development team poses a question to be answered in forthcoming projects. With reference to a combination of the disciplines industrial design, interface and interaction design, the defined objectives for the products' practical, aesthetic and symbolic functions are addressed in the design concept development in form of design sketches, paper models and mock-ups. The phase is concluded by the production of a design prototype.

This prototype is evaluated against the collected requirements originating of the process phase 'evaluate designs against requirements' with users of the target group. A refinement for this phase is suggested by the addition of the analysis of the evaluation results with regards to practical, aesthetical and symbolic product functions. The evaluation results build the basis for the iteration of the process phases till the overall results meet the defined project goals. 


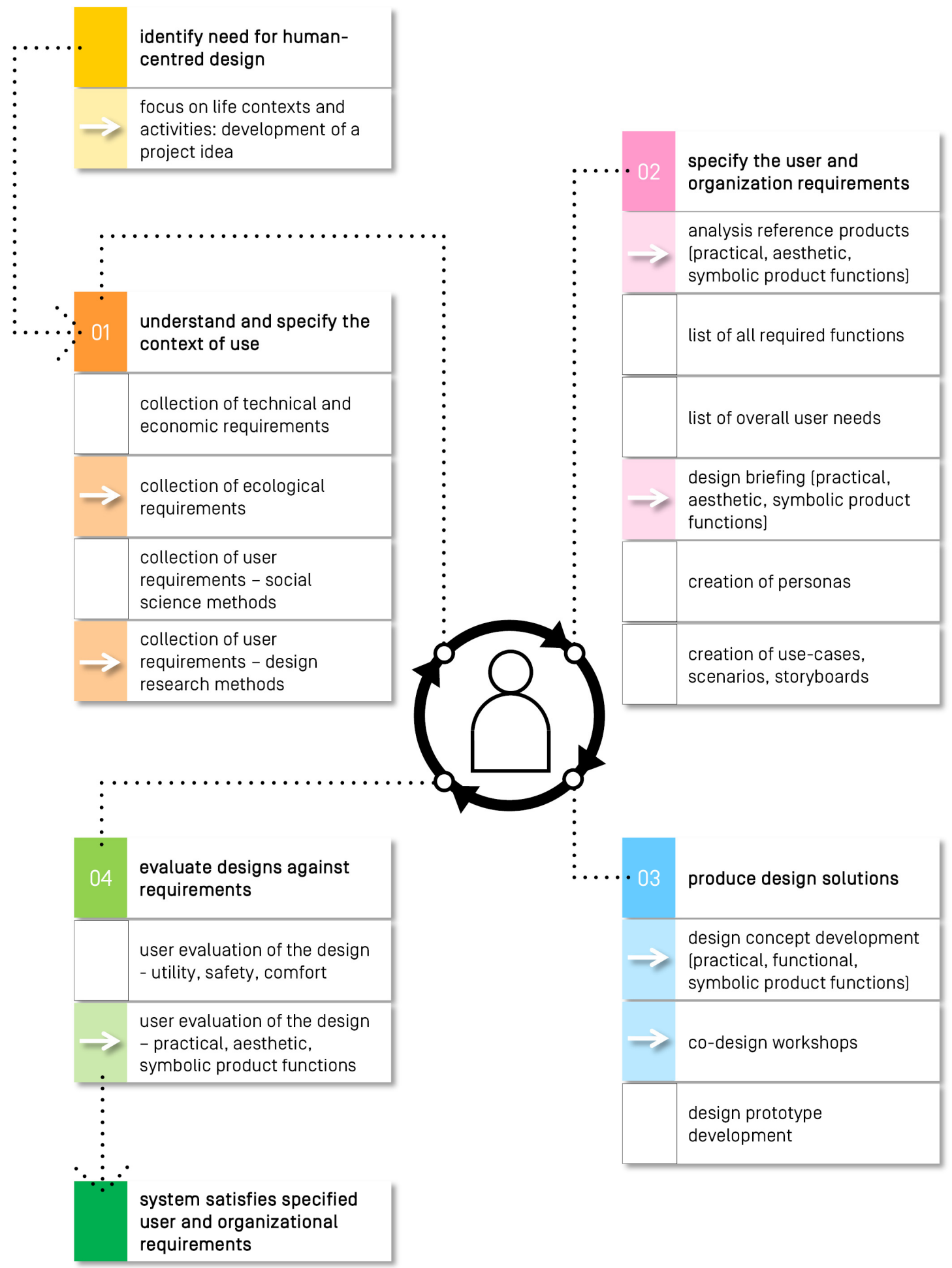

Figure 6. Representation of product design aspects in the user-centred design's ISOprocess

\section{Conclusion}

Product design has the potential to contribute to the overall consumer response and commercial success of a product. Since the calls of the AAL programme point to the importance of the development of 
market-oriented ICT-products, the discussion about the representation of product design aspects in the most frequently applied user-centred design's ISO process model seems adequate. This paper's aim was not to present a new process model for human-centred design in itself, but to raise awareness of the representation of product design aspects in the user-centred design's ISO process model by suggesting refinements for each of its process phases. Practical work experience has shown that for the success of a project, developed by a multi-disciplinary team, a clear and structured overview of the project's development process, a shared understanding of the relevant terminology as well as a shared understanding of the tasks of each process phase is essential. The suggested refinements will be used in on-going projects as discussion material and as a basis for further elaborations on the harmonization of team collaboration for projects in this research area.

\section{Acknowledgements}

AAL-projects are co-funded by the AAL Joint Programme and the National Authorities and R\&D programs of the participating countries.

\section{References}

AAL Europe (2018), AAL Programme: Active and Assisted Living Programme, ICT for ageing well. [online] AAL Europe. Available at: http://www.aal-europe.eu/get-involved/i-am-a-research-organization-2/ (accessed 12.03.2018).

Brown, T. (2009), Change by Design: How design thinking transforms organisations and inspires innovation, Harper Collins Publishers, New York.

Cockton, G., Lárusdóttir, M., Gregory, P. and Cajander, Å. (2016), Integrating user-centred design in agile development, Springer, Cham. https://doi.org/10.1007/978-3-319-32165-3

Crilly, N., Moultrie, J. and Clarkson, P.J. (2004), "Seeing things: consumer response to the visual domain in product design", Design Studies, Vol. 25 No. 6, pp. 547-577. https://doi.org/10.1016/j.destud.2004.03.001

Design Thinking for Educators (2012), Design Thinking for Educators Toolkit, 2 nd Edition. [online] Available at: https://designthinkingforeducators.com/ (accessed 07.03.2018).

Diefenbach, S. and Hassenzahl, M. (2017), Psychologie in der nutzerzentrierten Produktgestaltung: MenschTechnik-Interaktion-Erlebnis, Springer, Berlin. https://doi.org/10.1007/978-3-662-53026-9

Eder, W.E. (2008), “Theory of Technical Systems and Engineering Design Science - Legacy of Vladimir Hubka”, Proceedings of DESIGN 2008 / the 10th International Design Conference, Dubrovnik, Croatia, May 19 - 22, 2008, The Design Society, Glasgow, pp. 19-30.

Eikhaug, O. (2012), Innovating with people: the business of inclusive design, Norwegian Design Council, Oslo.

Friedman, K. (2016), "Foreword”, In: Muratovski, G. (Ed.), Research for Designers: A Guide to Methods and Practice, Sage Publications, London, UK, pp. XXIII.

Gasson, S. (2003), "Human-Centered vs. User-Centered Approaches to Information System Design", Journal of Information Technology Theory and Application, Vol. 5 No. 2, pp. 29-46.

Giacomin, J. (2014), "What is Human Centred Design?", The Design Journal: An International Journal for All Aspects of Design, Vol. 17 No. 4, pp. 606-623. https://doi.org/10.2752/175630614X14056185480186

Hassenzahl, M. (2005), "The thing and I: understanding the relationship between user and product", In: Blythe, M.A., Overbeeke, K., Monk, A.F. and Wright, P.C. (Eds.), Funology, Springer, Dordrecht, pp. 31-42. https://doi.org/10.1007/1-4020-2967-5_4

Heimgärtner, R. (2014), "ISO 9241-210 and Culture? - The Impact of Culture on the Standard Usability Engineering Process", Proceedings of DUXU 2014 / the $3^{\text {rd }}$ International Conference of Design, User Experience, and Usability - User Experience Design Practice, Heraklion, Greece, June 22-27, 2014, Springer, Cham, pp. 39-48. https://doi.org/10.1007/978-3-319-07638-6_5

Heufler, G. (2004), Design Basics: From Ideas to Products, Niggli, Sulgen.

Heufler, G. (2016), Design Basics: Von der Idee zum Produkt, 5th ed., Niggli, Zürich.

Hubka, V. and Eder, W.E. (1996), Design Science: Introduction to the Needs, Scope and Organization of Engineering Design Knowledge, Springer, London. https://doi.org/10.1007/978-1-4471-3091-8

IDEO.org (2015), The Field Guide to Human-Centered Design. [online] IDEO.org. Available at: http://www.designkit.org/resources/1 (accessed 07.03.2018).

International Organization for Standardization (2017), ISO 9241-210:2010 Ergonomics of human-system interaction, part 210: human-centred design for interactive systems. [online] International Organization for Standardization. Available at: https://www.iso.org/standard/52075.html (accessed 05.10.2017).

Kothgassner, O.D., Felnhofer, A., Hauk, N., Kastenhofer, E., Gomm, J. and Kryspin-Exner, I. (2012), TUI: Technology Usage Inventory. [online] ICARUS (Information- and Communication technology Applications: 
Research on User-oriented $\quad$ Solutions). Available at: https://www.researchgate.net/publication/259292979_Technology_Usage_Inventory_TUI_Manual (accessed 02.11.2017).

Milton, A. and Rodgers, P.A. (2013), Research methods for product design, Laurence King, London.

Plattner, H., Meinel, C. and Weinberg, U. (2009), Design Thinking: Innovation lernen, Ideenwelten öffnen, miWirtschaftsbuch, FinanzBuch Verlag GmbH, München.

Prahalad, C.K. and Ramaswamy, V. (2004), "Co-creation experiences: the next practice in value creation", Journal of Interactive Marketing, Vol. 18 No. 3, pp. 5-14. https://doi.org/10.1002/dir.20015

Realpe-Muñoz, P., Collazos, C.A., Hurtado, J., Granollers, T. and Valasco-Medina, J. (2016), “An Integration of Usable Security and User Authentication into the ISO 9241-210 and ISO/IEC 25010:2011", Proceedings of HAS 2016 / the $4^{\text {th }}$ International Conference on Human Aspects of Information Security, Privacy, and Trust, Toronto, Canada, July 17-22, 2016, Springer, Cham, pp. 65-76. https://doi.org/10.1007/978-3-319-39381-0_7

Richter, M. and Flückiger, M. (2013), Usability Engineering kompakt: Benutzbare Produkte gezielt entwickeln, Springer, Berlin, Heidelberg. https://doi.org/10.1007/978-3-642-34832-7

Sanders, E.B.-N. and Stappers, P.J. (2008), "Co-creation and the new landscapes of design”, Co-Design, Vol. 4 No. 1, pp. 5-18. https://doi.org/10.1080/15710880701875068

Sanders, E.B.-N. and Stappers, P.J. (2012), Convivial design toolbox: generative research for the front end of design, BIS Publishers, Amsterdam.

Seybold, P.B. (2006), Outside innovation: how your customers will co-design your company's future, HarperCollins, New York.

Steen, M. (2011), "Tensions in human-centred design”, Co-Design, Vol. 7 No. 1, pp. 45-60. https://doi.org/10.1080/15710882.2011.563314

Thomas, V., Remy, C. and Bates, O. (2017), "The Limits of HCD: Reimagining the Anthropocentricity of ISO 9241-210", Proceedings of LIMITS'17/ 2017 Workshop on Computing Within Limits, Santa Barbara, USA, June 22-24, 2017, ACM, New York, pp. 85-92. https://doi.org/10.1145/3080556.3080561

Tseng, M.M. and Piller, F.T. (2003), The customer centric enterprise: advances in mass customization and personalization, Springer, Berlin. https://doi.org/10.1007/978-3-642-55460-5

van Gorp, T. and Adams, E. (2012), Design for emotion, Morgan Kaufmann, Waltham, Mass.

von Hippel, E. (2005), Democratizing innovation, MIT Press, Cambridge, MA.

Prof. Dr. Sandra Dittenberger

New Design University St. Pölten, Faculty of Design

Mariazeller Straße 97a, 3100 St. Pölten, Austria

Email: sandra.dittenberger@ndu.ac.at 